\title{
UMA ANÁLISE DAS ECONOMIAS DE AGLOMERAÇÃO E SEUS EFEITOS SOBRE OS SALÁRIOS INDUSTRIAIS BRASILEIROS ${ }^{(*)}$
}

\author{
Cassiano Ricardo Dalberto ${ }^{a}$ \\ Jefferson Andronio Ramundo Staduto
}

RESUMO: O presente artigo investiga a influência das economias de aglomeração, subdivididas em economias de especialização/localização e urbanização/diversificação, sobre os salários industriais brasileiros nos anos de 2001 e 2010. A análise se deu sobre 84 pólos industriais, e foram aplicados os métodos de análise de componentes principais (ACP) e regressão econométrica, encontrando evidências de economias de urbanização, mas não de economias de especialização, e também constatando que o quadro de disparidades regionais pouco se alterou ao longo da década abordada.

PALAVRAS-CHAVE: Economias de aglomeração; indústria brasileira; salários industriais; economias de especialização; economias de urbanização.

CLASSIFICAÇÃO JEL: J31.

* Artigo recebido em 12/9/2012 e aprovado em 8/12/2013.

a Bacharel em Ciências Econômicas pela Universidade Estadual do Oeste do Paraná (UNIOESTE) e estudante do curso de mestrado do Programa de Pós-Graduação em Economia da Universidade Federal de Viçosa (UFV). Contato: cassianord@gmail.com.

b Doutor em Economia Aplicada pela Universidade de São Paulo, bolsista produtividade do CNPq e professor do Curso de Economia e do Programa de Pós-Graduação em Desenvolvimento Regional e Agronegócio da UNIOESTE, Campus de Toledo. Contato: jstaduto@yahoo.com.br. 


\title{
AN ANALYSIS OF THE AGGLOMERATION ECONOMIES AND ITS EFFECTS ON THE BRAZILIAN INDUSTRIAL WAGES
}

\begin{abstract}
The present work investigates the influence of agglomeration economies, subdivided in specialization/localization and urbanization/diversification economies, over the Brazilianindustrial wages in the years of 2001 and 2010. The analysis was took over 84 industrial poles, and it were applied the methods of principal component analysis (PCA) and econometric regression, founding out evidences of urbanization economies, but not specialization economies, and also noting that the context of regional disparities has changed little in the course of the decade approached.
\end{abstract}

KEYWORDS: Agglomeration economies; Brazilian industry; industrial wages; specialization economies; urbanization economies. 


\section{INTRODUÇÃO}

O processo de urbanização brasileiro está estreitamente relacionado ao processo de industrialização, que encontra nas cidades o ambiente favorável para sua localização, incentivado pelas externalidades positivas geradas pela concentração das atividades econômicas, como apontado por Marshall (1920). Dessa maneira, não são apenas as economias internas às firmas que propiciam ganhos às mesmas, mas também as economias externas, isto é, aquelas advindas da concentração das atividades econômicas cujos benefícios ultrapassam os limites da empresa.

As economias de aglomeração podem ser definidas como os ganhos econômicos advindos da concentração geográfica das atividades produtivas. Tais ganhos podem se manifestar de diferentes formas: através da difusão local do conhecimento, da redução dos custos logísticos, do surgimento de atividades complementares, do adensamento do mercado de trabalho, entre outros. Entretanto, as forças aglomerativas podem se comportar como uma parábola, atingindo um ponto de máximo, e a partir de então proporcionando deseconomias de aglomeração. Como as atividades industriais são, sobretudo, urbanas, tais movimentos estão essencialmente ligados ao processo de expansão populacional e econômica das cidades.

Nesse sentido, é necessário assinalar a dinâmica urbana e industrial brasileira sob o ponto de vista dos diferentes tamanhos dos centros urbanos. De acordo com Andrade e Serra (1998), no período de 1950 a 1970 as cidades com mais de 500 mil habitantes foram as grandes alavancadoras do processo de crescimento urbano no país, chegando a representar 44\% da população urbana em 1970, contra 35\% em 1950. Segundo os autores, esse crescimento corresponde à consolidação do parque industrial nacional, ligado principalmente às indústrias de bens de capital e duráveis, que eram em grande medida dependentes dos fatores aglomerativos.

Já entre os anos de 1970 e 1990 há um movimento da população urbana em direção às cidades médias, que passam a crescer a taxas mais elevadas que os grandes centros metropolitanos, especialmente na década de 1980, como observou Maricato (2001). Parte desse movimento pode ser explicada pelas deseconomias de aglomeração que passam a existir nas metrópoles nesse período, levando muitas decisões de investimento a buscarem novos centros urbanos, onde as economias de aglomeração ainda se fazem presentes (Diniz, 1993). Para Andrade e Serra (1998), esse movimento possui um conjunto de causas adicionais: mudanças nos padrões locacionais das indústrias, periferização das metrópoles, políticas governamentais e expansão das fronteiras agrícolas e minerais, além de fatores endógenos destas cidades.

A partir da década de 1990 o setor industrial teve um importante crescimento, concomitante à dispersão das plantas industriais de novas firmas, assim como as que 
já estavam instaladas. Esse processo de relocalização foi motivado pelas deseconomias de aglomeração presentes em grandes metrópoles, sobretudo São Paulo, e também por outros fatores, como a busca das firmas por regiões com menor densidade sindical, mão de obra mais barata e incentivos fiscais (Carleial, 1997). A despeito desses movimentos, Galinari et al. (2007), analisando o cenário segundo a ótica dos salários industriais e sua relação com as economias de aglomeração, constataram que as mudanças ocorridas na década não foram capazes sequer de mitigar a heterogeneidade salarial nas cidades médias e grandes.

Neste cenário de dispersão produtiva e especialmente industrial, o presente trabalho busca avaliar em que medida as economias de aglomeração impactam sobre os salários industriais no Brasil. As economias de aglomeração, subdivididas em economias de especialização e economias urbanas, têm recebido cada vez mais atenção das pesquisas em economia regional, que buscam compreender o fenômeno através de duas maneiras: i) por meio dos incrementos à produtividade do trabalho; e ii) através dos incrementos sobre os salários. Na literatura internacional, diversos trabalhos encontraram evidências de que as economias de aglomeração têm relação positiva tanto com a produtividade quanto com o salário (Rauch, 1991; Glaeser et al., 1992; Hanson, 1997; Henderson, 1999).

No caso brasileiro, a investigação utilizando a primeira via, isto é, a dos incrementos à produtividade é dificultada devido à carência dessas informações desagregadas a nível municipal. Portanto, o caminho utilizado nessa investigação foi o de relacionar as economias de aglomeração com os salários industriais.

Desta maneira, o objetivo do presente artigo é compreender as relações entre economias de aglomeração e os salários industriais entre os anos de 2001 e $2010^{1}$, período no qual preponderou um cenário econômico diferente daquele das décadas anteriores, marcado pela estabilidade econômica e pelo relativo crescimento da economia nacional, dos salários e da qualidade de vida ${ }^{2}$. Neste período ocorreram fundamentalmente novos investimentos, criando uma dinâmica de dispersão produtiva e, principalmente, industrial. Para atingir tal objetivo, foram obtidos dados da Relação Anual de Informações Sociais (RAIS) e utilizou-se a análise estatística multivariada, além de ter sido estimada uma equação de salários, de modo a verificar quais fatores aglomerativos estão mais associados com os salários na indústria.

1 Nesse sentido, o presente trabalho constitui uma extensão ao artigo publicado por Galinari et al. (2007), que analisou os efeitos das economias de aglomeração sobre os salários industriais na década de 1990, a partir dos dados do Censo.

2 Segundo o Programa das Nações Unidas para o Desenvolvimento, o Índice de Desenvolvimento Humano (IDH) brasileiro cresceu de 0,649 para 0,699 entre 2000 e 2010 (PNUD, 2011). 


\section{REFERENCIAL TEÓRICO}

As economias de aglomeração, compreendidas como um agrupamento de atividades econômicas, criadas e sustentadas por alguma lógica circular, podem ser verificadas em diferentes níveis regionais, e sua análise depende essencialmente do conceito de retornos crescentes. A economia distribui-se espacialmente de maneira irregular, o que se evidencia nas grandes disparidades existentes entre regiões que não são um produto de diferenças inerentemente locais, mas sim de um conjunto de processos cumulativos que inevitavelmente envolvem algum tipo de retorno crescente, permitindo reforçar a concentração geográfica (Fujita, Krugman e Venables, 2002).

De modo a explicar a concentração espacial, utilizam-se os conceitos de economias externas, introduzidos por Marshall (1920). De acordo com o autor, além das economias internas relacionadas à escala de produção da firma, existem também fontes de ganhos externos, relacionados à concentração geográfica da indústria. Essas fontes são classificadas por Marshall em três tipos: i) transferências de conhecimento entre pessoas e empresas de uma mesma atividade; ii) efeitos de encadeamento para frente e para trás; e iii) grandes mercados de trabalho especializado.

De acordo com as teorias locacionais, podem-se distinguir forças que atuam na concentração espacial das atividades econômicas e forças que agem no sentido de dispersá-las. Segundo Weber (1929) existem dois grupos de fatores que influenciam na decisão de localização de uma indústria: fatores regionais e fatores aglomerativos ou desaglomerativos. Os fatores regionais referem-se aos custos de transporte e às diferenças geográficas no custo do trabalho; já os fatores aglomerativos dizem respeito às reduções de preço obtidas pelo uso mais econômico de maquinários ou pela indústria estar localizada onde ocorre um comércio auxiliar; e finalmente os fatores desaglomerativos são aqueles que afastam as empresas devido aos altos aluguéis.

Desta forma, é possível afirmar que existem forças que atuam tanto no sentido da concentração quanto da dispersão produtiva. Tais forças revelam-se presentes simultaneamente nas regiões, e em cada local a predominância de uma força sobre a outra irá depender da magnitude de seus efeitos sobre a decisão locacional dos agentes.

Diversos estudos buscam elucidar as principais variáveis que levam os salários a serem diferenciados em regiões mais aglomeradas, ou seja, como as economias de aglomeração afetam os salários. De modo geral, os salários mais elevados estão associados a maiores níveis de capital humano, exigidos por atividades mais especializadas e mercados de trabalho mais densos, mas maiores níveis educacionais, por sua vez, relacionam-se positivamente com altos níveis de desenvolvimento econômico, que, 
por sua vez, estão associados a outros fatores que em geral levam a salários mais elevados, como um maior grau de tecnologia e estoque de capital físico per capita ${ }^{3}$.

Outro fator de influência que pode ser considerado é o diferencial de custo de vida e bem-estar entre grandes centros urbanos e cidades menores. Nessa visão, as empresas pagariam salários maiores para compensar o trabalhador pelos custos elevados de se morar em um grande centro, como os aluguéis elevados e as necessidades de transporte, além de recompensá-lo pela redução da qualidade de vida decorrente, por exemplo, de maior poluição, violência e congestionamentos.

Mais recentemente, Glaeser et al. (1992) propuseram uma subdivisão das economias de aglomeração em duas categorias: as economias de especialização/localização, conhecidas também como Marshall-Arrow-Romer (MAR); e as economias de urbanização/diversificação, ou de Jacobs. Ambas são economias externas à firma; porém, enquanto as economias de especialização são aquelas relacionadas às economias internas à aglomeração de uma mesma indústria, proporcionadas por aumentos na escala produtiva e pelas transferências de conhecimento (spillovers informacionais) dentro de uma indústria ou indústrias correlatas, as economias de urbanização referem-se aos ganhos pela transferência de conhecimento entre diferentes indústrias, atestando que não é a especialização e sim a diversificação que contribui positivamente para a produtividade da economia local.

Segundo Jacobs (1969), quanto maior o número e a variedade de divisões do trabalho em uma economia, maior será a capacidade inerente dessa economia em adicionar ainda mais tipos de bens e serviços. Para a autora, o crescimento e o desenvolvimento urbanos só podem ser sustentados ao longo do tempo por meio de um processo de constante adição de novos tipos de trabalho. Assim, cidades que, ao invés disso, permanecem apenas repetindo o mesmo tipo de trabalho não se expandem muito, nem conseguem se desenvolver.

As economias de especialização/localização, por sua vez, remontam à obra de Marshall (1920), para quem as vantagens da proximidade beneficiariam as atividades especializadas, levando os conhecimentos a ficarem "soltos no ar" e, com isso, proporcionam o surgimento de atividades subsidiárias e reforçam a especialização. Esses spillovers informacionais geram externalidades positivas, que estimulam a aglomeração das atividades econômicas. Segundo a visão de Marshall, é a captação dessas externalidades pelas empresas de uma mesma indústria que leva a um maior desenvolvimento da atividade industrial em uma cidade e a maiores ganhos de escala, com acréscimos na produtividade.

O debate entre qual tipo de economias de aglomeração, MAR ou de Jacobs, é responsável por maiores ganhos no contexto urbano-industrial, tanto para empresas

\footnotetext{
3 Para uma discussão mais aprofundada, ver Rauch (1991) e Wheaton e Lewis (2002).
} 
quanto para trabalhadores, permanece inconclusivo e abre espaço para pesquisas que abordem o tema. Trabalhos como os de Henderson (1999) e Kemeny e Storper (2012) para os EUA, Van der Panne (2004) para a Holanda, e Dekle (2002) para o Japão, encontraram a presença de economias de especialização. Por outro lado, os trabalhos de Glaeser et al. (1992) e Henderson, Kuncoro e Turner (1995), ambos analisando os EUA, encontraram evidências de externalidades positivas de urbanização.

Kaulich (2012) encontra resultados que sugerem a ideia de que a relação da diversificação/especialização com a renda, em um dado país, depende justamente do nível atual de renda do mesmo, ideia sugerida inicialmente por Imbs e Wacziarg (2003), para quem a relação entre especialização e renda se dá através de uma curva em formato de "U". Os resultados de Kaulich (2012) indicam que, em países com menor nível de renda per capita, a diversificação está positivamente relacionada com a renda, enquanto que para países com nível de renda mais elevado não há evidências que permitam concluir que tal relação possa se tornar negativa. Já Beaudry e Schiffauerova (2009), após analisarem diversos estudos sobre o tema, concluem que os diferentes resultados obtidos não se devem, em geral, às diferenças entre as intensidades das forças aglomerativas entre indústrias, países ou períodos de tempo, e sim a questões metodológicas e de medição.

No contexto brasileiro, Galinari et al. (2007) obtiveram resultados que demonstram a presença de economias de urbanização correlacionadas com altos salários, ao mesmo tempo em que argumentam que, apesar de não se verificarem economias de especialização, não é prudente afirmar que as mesmas não existem, dada a realidade idiossincrática das economias regionais brasileiras. Deste modo, os autores limitam-se a atestar que tais evidências apenas apontam que, no Brasil, as condições que levam ao surgimento de economias de especialização ainda são fracas.

Catela, Gonçalves e Porcile (2010), ao analisarem 524 municípios brasileiros, encontram resultados que indicam maior importância das economias de diversificação para a maior parte dos municípios brasileiros, reforçando as constatações feitas por Galinari et al. (2007). Ao mesmo tempo, os autores dão suporte à ideia de que a diversificação é mais importante nos municípios de baixa renda, enquanto que a especialização proporciona maiores ganhos para as cidades de maior nível de renda, o que está em consonância com os trabalhos de Carvalho e Kupfer (2012) e Kaulich (2012), mas no nível municipal.

É importante salientar que os conceitos de economias de urbanização/diversificação e especialização/localização não são necessariamente mutuamente excludentes. Eles oferecem diferentes pontos de vista que buscam identificar qual característica é mais importante para a promoção de externalidades que conduzem ao crescimento e ao desenvolvimento econômicos. 


\section{AGLOMERAÇÃO E DISPERSÃO: TRAJETÓRIA BRASILEIRA}

Até o final da década de 1960 a produção brasileira concentrou-se quase que exclusivamente nas regiões metropolitanas de São Paulo e Rio de Janeiro, com destaque maior para a primeira, caracterizando o Sudeste como o centro dinâmico nacional. A partir dos anos de 1970 a região metropolitana de São Paulo (RMSP) passa a apresentar deseconomias de aglomeração, ao mesmo tempo em que começam a surgir economias de aglomeração em outros centros urbanos. Entretanto, de acordo com Diniz (1993), esses novos centros tenderam a se concentrar em um polígono ao redor da cidade de São Paulo (delimitado por Belo Horizonte - Uberlândia - Londrina/Maringá - Porto Alegre - Florianópolis - São José dos Campos - Belo Horizonte), conferindo um caráter restrito à desaglomeração.

Por outro lado, Negri (1996) salienta que, apesar do polígono apontado por Diniz (1993) ter sido o maior beneficiado pela desconcentração industrial entre 1970 e 1990, aumentando sua participação na indústria nacional de $33,1 \%$ para $49,2 \%$, as demais regiões fora do polígono também cresceram relativamente no período, à exceção da Grande São Paulo e do Rio de Janeiro. A participação do Nordeste (exceto pela Bahia) manteve-se praticamente estável, ao passo que Espírito Santo, Bahia e os estados do Norte e Centro-Oeste incrementaram sua participação de 3,6\% da transformação nacional em 1970 para aproximadamente 10,2\% em 1990.

As cidades médias começaram a aparecer no cenário brasileiro pós-1970 como receptáculos favoráveis às decisões de novos investimentos, por possuírem qualidades atrativas às empresas, como infraestrutura geradora de economias externas, mercado consumidor denso e também capital humano relativamente desenvolvido, sem, entretanto, incorrer em deseconomias de aglomeração. Desta forma, as cidades médias passaram a apresentar maiores taxas de crescimento populacional comparativamente às metrópoles. Segundo Maricato (2001), enquanto as metrópoles cresceram a uma taxa média anual de 1,3\% nos anos 1980 e 1990, as cidades médias apresentaram um crescimento médio anual de 4,8\% no mesmo período, ou seja, uma taxa 3,7 vezes superior àquela.

Na década de 1980, contudo, o movimento de desconcentração sofreu um arrefecimento, sobretudo devido às preocupações quase que exclusivas com a instabilidade monetária de então, o que conduziu, conforme Diniz e Crocco (1996), a um enfraquecimento do papel do Estado no investimento direto e na operação de políticas regionais. Castro (2001) assinala que, enquanto no mundo desenvolvido ocorria uma renovação nos métodos organizacionais, de gerenciamento e de produção, no Brasil, especialmente na segunda metade daquela década, as mudanças no lado real da economia cessaram. Ao mesmo tempo em que o país perdia market share nos mercados mundiais, as indústrias nacionais, de maneira geral, apenas conseguiam sobreviver, ficando à margem do processo de renovação que ocorria nas regiões industrializadas. 
A partir de 1988, por meio da nova Constituição, consagram-se conquistas trabalhistas históricas e criam-se novos direitos relevantes no âmbito do mercado de trabalho. A partir desse período, sinaliza-se um retorno das forças de dispersão produtiva, que viriam de fato a se intensificar na década de 1990, principalmente em razão da abertura comercial, desregulamentação da economia, privatizações e estabilidade monetária, os quais propiciaram a entrada de novos investimentos no país. De acordo com Sabóia (2001), as principais regiões beneficiadas nesse período foram o Sul e o Centro-Oeste.

Galinari et al. (2007), ao investigarem os efeitos das economias de aglomeração sobre os salários industriais, concluíram que entre 1991 e 2000 as mudanças políticas e econômicas ocorridas sequer mitigaram a heterogeneidade da estrutura salarial dos mesopolos brasileiros ${ }^{4}$. Além disso, apesar da existência de economias de urbanização no Brasil, os fatores responsáveis pelo surgimento de economias de especialização ainda eram incipientes.

Carvalho e Kupfer (2012), seguindo o procedimento empírico utilizado por Imbs e Wacziarg (2003), encontram a mesma curva em formato de " $U$ " preconizada por estes autores, tanto para o Brasil quanto para diversos outros países. Entretanto, o ponto de inflexão do caso brasileiro é bastante precoce em termos de renda per capita quando comparado com os demais países. Tal movimento de retorno à especialização passou a ocorrer a partir da década de 1980, tendo se acentuado na década de 1990, o que pode ser, segundo os autores, fruto da abertura comercial.

Dados estes aspectos teóricos, o item 4 apresenta os procedimentos metodológicos utilizados com vistas a obter informações para a posterior avaliação e interpretação das relações entre as economias de aglomeração e os salários industriais brasileiros, que é realizado no item 5 .

\section{METODOLOGIA}

\subsection{RECORTE REGIONAL}

O presente trabalho investiga a presença de economias de aglomeração e suas relações com os salários industriais em cidades médias e grandes no Brasil, dimensionadas em 84 meso e macropolos definidos segundo a metodologia de regionalização proposta por Lemos et al. (2003). Cada polo foi caracterizado pelos autores de acordo com seu entorno e nível de renda, utilizando as seguintes classificações: enclave (entorno de subsis-

${ }^{4}$ Os mesopolos considerados por Galinari et al. (2007) constituem-se nas microrregiões geográficas (MRGs) definidas na regionalização de Lemos et al. (2003), que também é utilizada no presente trabalho. 
tência e/ou renda baixa); regiões isoladas (entorno de renda baixa e/ou renda média baixa); polo econômico (entorno predominantemente de renda média alta e elevada).

Segundo o trabalho de Simões e Amaral (2011), houve estabilidade da hierarquia urbana entre 1993 e 2007, não se modificando os graus hierárquicos das cidades interioranas do Brasil, a despeito de parcela dos municípios que avançaram no sistema de cidades. Desta forma, assume-se que os polos identificados por Lemos et al. (2003) não sofreram alterações substanciais que acarretassem perda de centralidade ao longo deste últimos anos. Entretanto, não se exclui a possibilidade de que tal hierarquia possa vir a se alterar com os investimentos realizados ao longo da década de $2010 \mathrm{em}$ muitas localidades, principalmente oriundos de políticas públicas, como, por exemplo, o Programa de Aceleração do Crescimento do Governo Federal.

Como o estudo é realizado considerando como unidade de análise as cidades polos, as quais estão distantes entre si porque elas refletem o campo de influência sobre as cidades vizinhas, não são realizadas análises de vizinhança.

A Figura 1 apresenta a distribuição da regionalização de Lemos et al. (2003) no mapa do Brasil, no qual é possível visualizar as áreas de influência de cada macropolo:

Figura 1 - Macropolos brasileiros e suas áreas de influência

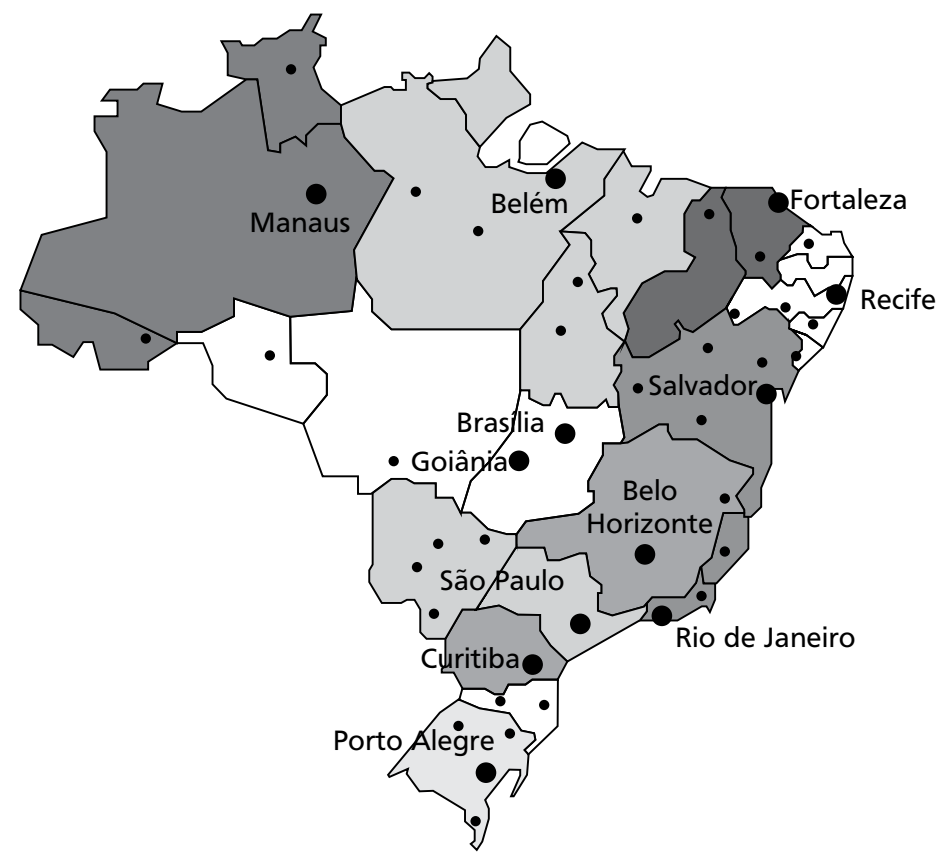




\subsection{BASE DE DADOS E VARIÁVEIS}

A base de dados utilizada foi a Relação Anual de Informações Sociais (RAIS), para os anos de 2001 e 2010. A RAIS é um levantamento anual realizado pelo Ministério do Trabalho e Emprego (MTE), abrangendo todo o território nacional. É necessário pontuar que a RAIS abrange apenas o mercado formal.

A desagregação setorial foi realizada segundo a Classificação Nacional de Atividades Econômicas (CNAE) segundo a classificação 1.0, em virtude de ser a única classificação disponível na RAIS para ambos os períodos abordados. Foram escolhidas as seções C, D e F da CNAE, que representam, respectivamente, os setores de Indústrias Extrativas, Indústrias de Transformação e Construção, perfazendo um total de 28 subdivisões setoriais para a indústria.

O nível de desagregação de dois dígitos da CNAE a partir dos dados da RAIS é consistente com vários estudos que analisam a distribuição das atividades no território nacional, em termos de país, macrorregiões e estados, bem como os salários, tais como os de Sperotto e Peyré-Tartaruga (2009), Rezende, Campolina e Paixão (2012), Galinari et al. (2007), entre outros. Vários trabalhos que analisam e agrupam as indústrias segundo o grau de sua dinâmica tecnológica também utilizam dois dígitos CNAE, os quais impactam fortemente no nível de remuneração do trabalho (Passos e Lima, 2000; Lima, 2003; Furtado e Carvalho, 2005).

As variáveis utilizadas basearam-se naquelas escolhidas por Galinari et al. (2007). Algumas delas foram adaptadas, em virtude das diferenças entre as bases de dados utilizadas, enquanto que a inclusão da população total constitui contribuição original deste trabalho. Desta forma, foram aplicadas as variáveis conforme segue:

a) Salário/hora médio industrial: consiste na variável "remuneração média do trabalhador", dividida pelo total de horas trabalhadas por mês.

b) Grau de instrução: essa variável representa a média dos anos de instrução, como uma medida do capital humano ocupado na indústria.

c) Concentração industrial: obtida por meio do cálculo da participação relativa do emprego industrial local sobre o nacional, expressando a ideia de densidade e escala da indústria dos mesopolos.

d) Especialização/diversificação produtiva local $(\mathrm{HH})$ : essa variável demonstra a variabilidade da especialização/diversificação produtiva entre as cidades, e foi utilizada a fim de investigar se é a diversidade ou a especialização produtiva que influencia de maneira positiva os salários locais (Galinari et al., 2007). Esse índice é conhecido como Hirschman-Herfindahl ( $\mathrm{HH})$ ou ElisonGlaeser ajustado, de acordo com Henderson (1999), e é calculado da seguinte maneira: 


$$
H H i=\sum_{j=1}^{n}\left[\left(E_{i j} / E_{i}\right)-\left(E_{j} / E_{p}\right)\right]^{2}
$$

Em que:

$E_{i j}$ : Emprego na cidade $i$ no setor $j$;

$E_{i}$ : Total do emprego industrial na cidade $i$;

$E_{j}$ : Emprego nacional no setor $j$;

$E_{p}$ : Total do emprego industrial no país;

$n: 1,2,3, \ldots, 28$ são os setores industriais.

Desta forma, quando a indústria de uma cidade $i$ for perfeitamente desconcentrada (diversificada) o valor do índice será zero. O outro extremo, quando a cidade é totalmente concentrada (especializada), é representado pelo valor máximo do índice, ou seja, $\mathrm{HH}=2^{5}$.

e) Emprego em grandes empresas: foi calculada a participação dos empregos em grandes empresas industriais ${ }^{6}$ em relação ao total da indústria local, a fim de se averiguar se são as economias internas, externas ou ambas que influenciam os salários industriais. Essa variável foi utilizada somente na análise de componentes principais (ACP).

f) População total: tal variável representa uma proxy para o tamanho dos centros urbanos, e por consequência também representa uma proxy para os custos de vida, que tendem a ser mais elevados nas maiores cidades. Tal variável foi obtida do Censo Demográfico realizado pelo Instituto Brasileiro de Geografia e Estatística (IBGE) para os anos de 2000 e 2010. Essa variável foi utilizada apenas na regressão.

É importante salientar a diferença entre a base de dados utilizada no trabalho de Galinari et al. (2007) e neste trabalho, respectivamente, o Censo Demográfico e a RAIS. Enquanto que os dados censitários abrangem tanto os trabalhadores formais quanto os informais, os dados da RAIS captam apenas trabalhadores formais, o que pode acarretar em resultados diferentes entre os trabalhos. Todavia, os dados da RAIS para o setor industrial tendem a ser relativamente próximos aos do Censo, porque a informalidade neste setor é menor em relação os demais setores da economia. Ainda,

5 Além de Galinari et al. (2007), podem-se mencionar diversos outros trabalhos que utilizam o índice $\mathrm{HH}$ como medida de especialização/diversificação, como Henderson, Kunkoro e Turner (1995), Henderson (1999), Dekle (2002), Kemeny e Storper (2012), entre outros.

6 De acordo com o Sebrae (2011), grandes empresas industriais são aquelas que possuem mais de 500 trabalhadores. Informação disponível em: <http://www.sebrae-sc.com.br/leis/default.asp?vcdtexto=4154>. 
os dados do Censo são atualizados apenas a cada dez anos; por outro lado, os da RAIS estão disponíveis anualmente, permitindo uma atualização mais frequente, por exemplo, entre os períodos censitários.

Apesar da vantagem de possuir dados com grande nível de desagregação, a RAIS não é imune a críticas, o que torna necessário algumas considerações. Suzigan et al. (2000) resumem os problemas da RAIS em três pontos. Em primeiro lugar está o fato da base de dados considerar apenas os empregos formais, o que exclui uma parcela considerável dos trabalhadores, problema que se torna maior em áreas menos desenvolvidas, onde a informalidade em geral é maior. Um segundo problema diz respeito à possibilidade de que firmas que operem com diversas plantas em diferentes regiões possam lançar os dados sobre seus trabalhadores em localidade diferente daquela onde eles efetivamente se encontrem. Finalmente, o terceiro problema se refere à questão da auto-classificação, pela empresa, do setor ao qual ela se enquadra, o que pode gerar distorções. Tal viés tende a ser menor em regiões onde ocorrem aglomerações industriais especializadas do que em regiões onde há pulverização das atividades, situação que não cria tão facilmente uma cultura setorial que favoreça o correto enquadramento.

\subsection{MÉTODOS DE ANÁLISE}

Em um primeiro momento, foi utilizada a Análise de Componentes Principais (ACP $)^{7}$, que consiste num método estatístico multivariado que objetiva condensar uma série de informações, de modo que sua análise seja simplificada. Pretende-se, desta maneira, que a ACP mostre como eram as dotações relativas de algumas variáveis relacionadas à indústria nos períodos de 2001 e 2010. São variáveis associadas ao capital humano, às economias de aglomeração e às economias de escala interna entre os mesopolos brasileiros. Busca-se, por meio desse procedimento, identificar quais atributos podem influenciar positiva ou negativamente os salários industriais para os pólos definidos. Como diversas variáveis podem estar relacionadas aos salários, agregá-las através da ACP permite obter resultados mais claros e de interpretação mais objetiva. Além disso, a utilização dos componentes principais permite obter uma visualização gráfica que pode fornecer uma melhor compreensão das relações de tais variáveis com os salários.

Uma etapa importante para a utilização da ACP consiste na verificação da adequabilidade da amostra à utilização do método. Para tanto, diferentes métodos visam fornecer informações que permitam atestar tal adequação. O teste Kaiser-Meyer-Olkin

\footnotetext{
Detalhes metodológicos ver em Hoffmann (1999).
} 
(KMO) e o teste de esfericidade de Bartlett são duas das principais medidas do ajuste da amostra à análise de componentes principais. Para o teste $\mathrm{KMO}$, a literatura recomenda que um nível acima de 0,5 é mais adequado para a realização da ACP. Já o teste de esfericidade de Bartlett testa a hipótese nula $\left(H_{0}\right)$ de que a matriz de correlação das variáveis é uma matriz identidade, ou seja, que não há correlação entre as mesmas, revelando inadequação para a ACP (Ho, 2006).

Posteriormente, foi utilizado um modelo econométrico para estimar equações de salários para os anos de 2001 e 2010. Através dessas estimações objetiva-se entender de que maneira as variáveis selecionadas estão relacionadas com os salários da indústria nos mesopolos brasileiros. Ainda que a ACP possa condensar as informações das variáveis utilizadas em componentes isentos de correlação, é importante analisar as relações individuais de cada variável com os salários industriais. Além disso, a utilização da regressão econométrica permite uma comparação mais direta com os trabalhos já realizados para o Brasil. O modelo utilizado foi o seguinte:

$$
\begin{gathered}
\log \text { Salário / Hora }=\beta_{0}+\beta_{1} \log \text { Instrução }_{i} \\
+\beta_{2} \log \text { Concent. Ind } ._{i} \\
+\beta_{3} \operatorname{LogH}_{i}+\beta_{4} \log \text { População } o_{i}+\varepsilon_{1}
\end{gathered}
$$

O nível de instrução busca captar os efeitos da dotação de capital humano dos indivíduos sobre seus salários. A concentração industrial representa uma medida das economias de aglomeração existentes, caso em que a variável deve assumir sinal positivo. A ocorrência de sinal negativo, por outro lado, indica a presença de deseconomias de aglomeração. A variável HH visa captar se são as economias de especialização ou de diversificação que são mais importantes para a elevação dos salários. Como valores maiores do índice denotam maior nível de especialização industrial, um coeficiente positivo para o mesmo significa que a especialização gera ganhos salariais para os indivíduos. Entretanto, caso o sinal seja negativo, tem-se que a diversificação é a responsável por tais ganhos. Por fim, a população é uma proxy que visa captar os custos de vida locais, que tendem, em geral, a ser mais elevados nos maiores centros urbanos.

A estimação das variáveis logaritmizadas diminui a heterogeneidade dos dados e fornece os resultados dos parâmetros em termos de elasticidade. O modelo foi estimado utilizando-se o método dos Mínimos Quadrados Ordinários (MQO) ${ }^{8}$.

\footnotetext{
8 Outros métodos foram considerados, como a regressão quantílica. Entretanto, as regressões quantílicas não forneceram bom ajuste aos dados, não permitindo obter inferências sobre as variáveis do modelo. Pontua-se também a importância de modelos simples, mas que tenham capacidade de explicação adequada, e de sua preferência a modelos mais complexos que tenham a mesma capacidade explicativa, o que está de acordo com o princípio da parcimônia (também conhecida por Navalha de Ockham).
} 


\section{RESULTADOS E DISCUSSÃO}

\subsection{ANÁLISE MULTIVARIADA: A DOTAÇÃO DOS ATRIBUTOS DAS ECONOMIAS DE AGLOMERAÇÃO NOS MESOPOLOS BRASILEIROS}

A aplicação da análise de componentes principais (ACP) reduziu as cinco variáveis analisadas (salário/hora médio industrial, grau de instrução, concentração industrial, especialização produtiva local $[\mathrm{HH}]$ e emprego em grandes empresas) em dois componentes isentos de correlação. Utilizou-se a rotação varimax, que consiste num método ortogonal de rotação dos fatores, buscando minimizar sua covariância, e é, de acordo com Ho (2006), o mais utilizado dos métodos rotacionais, por fornecer a separação mais clara dos fatores.

A Tabela 1 apresenta a matriz dos componentes obtidos para 2001, além das informações relacionadas à extração dos componentes. Verifica-se que a maior parte da variância das variáveis originais $(66,87 \%)$ é explicada pelos dois componentes obtidos. $\mathrm{O}$ teste KMO apresentou um resultado inferior ao recomendado pela literatura, ficando em 0,4. Por outro lado, o teste de esfericidade de Bartlett revelou rejeição da hipótese nula ao nível de $1 \%$ de significância, o que significa que a amostra é adequada para realização de ACP, contrariando o resultado do teste KMO. Considerando que a maior parte da variância foi explicada pelos componentes, procedeu-se com a análise, mas se mantém a ressalva de que, dos dois testes realizados que indicam a adequabilidade amostral ao método, um deles rejeitou a utilização do método.

Tabela 1 - Matriz de componentes principais para 2001

\begin{tabular}{l|c|c}
\hline \multirow{2}{*}{} & \multicolumn{2}{|c}{ Componente } \\
\cline { 2 - 3 } & $\mathbf{1}$ & $\mathbf{2}$ \\
\hline Salário/hora & 0,833 & $-0,068$ \\
\hline Grau de instrução & 0,741 & $-0,450$ \\
\hline Concentração industrial & 0,366 & $-0,547$ \\
\hline Especialização produtiva (HH) & 0,240 & 0,887 \\
\hline Emprego em grandes empresas & 0,751 & 0,228 \\
\hline Adequação da amostra segundo critério KMO & & 0,398 \\
\hline Significância do teste de esfericidade de Bartlett & & 0,000 \\
\hline Variância total explicada & & $66,87 \%$ \\
\hline
\end{tabular}

Fonte: Elaboração própria.

Os resultados obtidos revelam uma maior influência do salário/hora, do grau de instrução e do emprego em grandes empresas no componente 1, enquanto que a concentração industrial e a especialização produtiva estão mais associados ao componente 
2, sendo que a concentração industrial possui associação negativa com este componente. Desta forma, optou-se por nomear o componente 1 como "desenvolvimento urbano-empresarial", que demonstra a associação do capital humano com o salário médio das indústrias e com as grandes empresas. O componente 2 refere-se à "concentração industrial diversificada", onde centros com maior grau de especialização são aqueles que possuem relativamente menor concentração industrial (visualizado pelo sinal negativo da variável), ou seja, as cidades com maior peso industrial dentro do cenário nacional são, também, as mais diversificadas.

A associação da participação do emprego em grandes empresas aos elevados salários e grau de instrução na indústria em 2001 pode ser explicada em parte pelo contexto de abertura comercial da década anterior, em que a concorrência externa afetou diretamente a lucratividade e a sobrevivência de muitas empresas nacionais, que se viram obrigadas a reestruturar seus modos de produção para enfrentar este cenário. As grandes empresas, de modo geral, participam de estruturas de mercado mais oligopolizadas, o que aumenta o grau de proteção a choques negativos por meio de vários mecanismos de ajustamento, enquanto que as pequenas e médias empresas não possuem a mesma capacidade de ajuste, estando mais suscetíveis aos efeitos negativos da abertura comercial. Nesse sentido, a prática do downsizing nas grandes empresas acarretou em redução de seus quadros funcionais, de modo que a maior parte dos cargos remanescentes nestas, muito provavelmente foram aqueles ligados a atividades mais qualificadas.

Já o resultado do componente 2 , da “concentração industrial diversificada”, onde a concentração da indústria está negativamente relacionada à especialização, revela concordância com a proposição de Jacobs (1969), para quem as cidades que não são capazes de adicionar novos bens e serviços à sua economia - isto é, inovar e diversificar sua produção - não são capazes de se expandir e se desenvolver muito.

A Figura 2 apresenta os resultados dos componentes de 2001 biplotados em eixos partindo do ponto zero, que consiste na média de ambos os componentes, bem como os pontos para cada mesopolo. Considerando os resultados da ACP, a Figura 2 mostra a dispersão das cidades em relação aos valores dos componentes obtidos. Assim, quanto mais afastado um município está da intersecção dos eixos, digamos, para cima (valores positivos), maiores serão os salários médios, o grau de instrução e o emprego em grandes empresas, pois são estas as variáveis mais fortemente associadas ao componente 1, cuja escala é representada verticalmente. Partindo da mesma ideia e considerando o componente 2, quanto mais um município se afasta para a direita (valores positivos), maior será sua especialização produtiva mensurada pelo índice $\mathrm{HH}$ e, de forma contrária, quanto mais à esquerda ele estiver situado (valores negativos), mais diversificada industrialmente será a cidade. A interpretação inversa é feita para a concentração industrial: quanto mais à esquerda o município estiver, maior é sua participação na indústria nacional; e quanto mais à direita, menor. 
Figura 2 - Os componentes principais de 2001

5

4

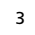

2 São Paulo

3

São José dos Campos

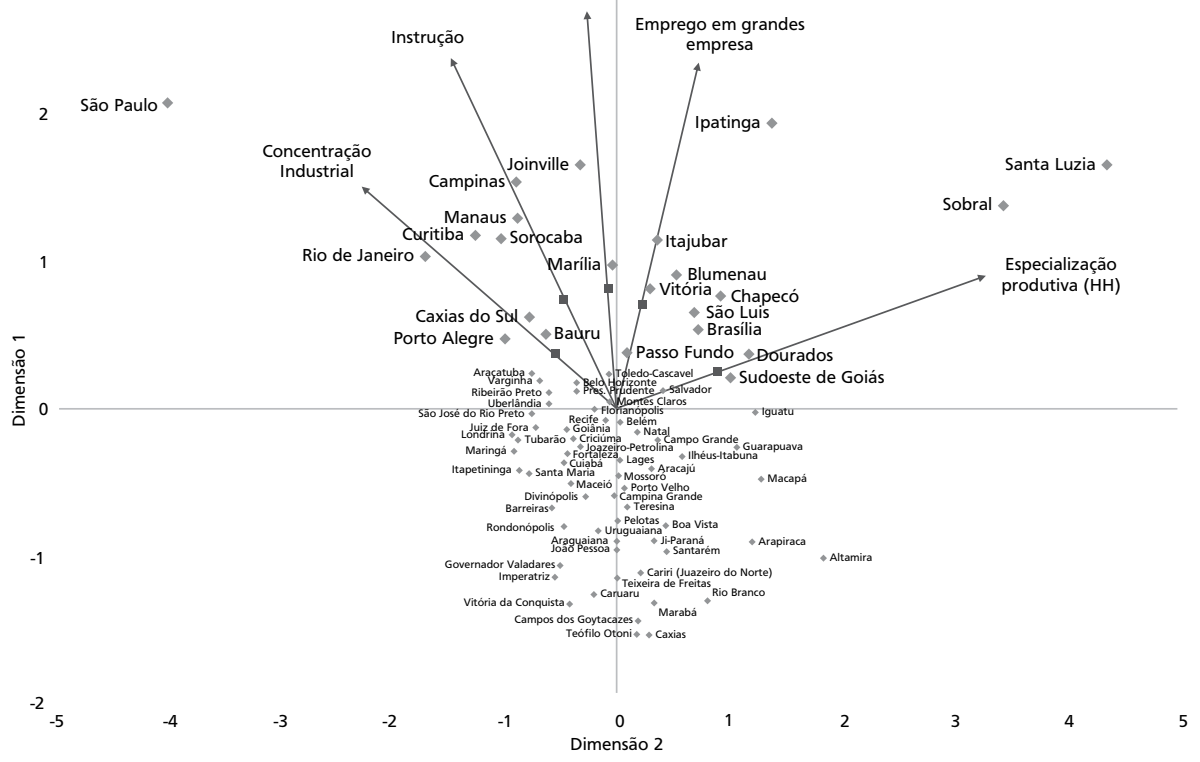

Fonte: Elaboração própria.

Observa-se que em 2001 a maioria dos municípios estava localizada abaixo da média nos quesitos do componente 1 , isto é, estava abaixo da média em termos de salário/hora médio industrial, grau de instrução e emprego em grandes empresas. Em contrapartida, existem municípios com valores consideravelmente maiores que a média, como São José dos Campos, cujo salário/hora médio era de R\$11,32, bastante acima da média de $\mathrm{R} \$ 3,37$. O mesmo observou-se para os anos de estudo da mesma cidade, que no período foi de 11 anos, contra 8,45 anos da média.

No que se refere especificamente ao nível de instrução, das 10 cidades com maior nível de instrução na indústria, sete eram do Sudeste (São José dos Campos, Volta Redonda, Sorocaba, Marília, Campinas, Varginha e Araçatuba), sendo que cinco destas pertencem ao Estado de São Paulo, revelando uma alta concentração espacial dessa variável. Manaus, uma das exceções, é uma cidade marcada pela sua Zona Franca, 
criada em 1967, onde predominam indústrias de fabricação de materiais eletrônicos, de alto valor tecnológico agregado. Joinville, outra das cidades não localizadas no Sudeste, tinha como principal setor em 2001 a fabricação de máquinas e equipamentos, seguido pela metalurgia básica e pela fabricação de artigos de borracha e plástico. Por fim, a outra cidade fora do Sudeste, Curitiba, possuía maior participação na indústria da construção, automobilística e alimentos e bebidas. Levando em consideração o polígono da desconcentração industrial mencionado por Diniz (1993), Manaus permanece sendo a única destas cidades a estar fora do centro gravitacional da desconcentração industrial.

A Figura 2 revela que todas as cidades paulistas mencionadas se localizavam no primeiro quadrante, isto é, o superior esquerdo, com instrução, salário/hora e emprego em grandes empresas acima da média, e também abaixo da média de especialização produtiva e acima da média da concentração industrial, sendo que as cidades do entorno da RMSP e a própria cidade de São Paulo possuíam níveis mais elevadosnas dotações do componente do "desenvolvimento urbano-empresarial" do que as cidades do interior do estado.

Em 2001 os cinco maiores salários industriais encontravam-se no Sudeste: além de São José dos Campos, figuravam nessa lista os municípios de Volta Redonda, Campinas, São Paulo e Sorocaba. Por outro lado, os municípios com menores níveis salariais pertenciam em geral ao Nordeste (Arapiraca, Caruaru, Juazeiro do Norte e Iguatu), somado ao município mineiro de Teófilo Otoni. Esses cinco municípios foram caracterizados na regionalização de Lemos et al. (2003) como enclaves agropecuários, ou seja, localidades cujo entorno urbano é predominantemente agropecuário e de renda baixa, ou mesmo de subsistência. Suas atividades industriais eram, em geral, voltadas para os setores mais básicos, como fabricação de alimentos e bebidas, produtos do fumo, artigos de couro e vestuário, etambém eram municípios cujos anos de instrução estavam abaixo da média em 2001.

A Tabela 2 apresenta os cinco municípios mais especializados e os cinco mais diversificados em 2001, conforme o índice HH. Percebe-se que os municípios mais especializados estavam majoritariamente localizados nas regiões Norte e Nordeste em 2001. Santa Luzia e Altamira concentravam seus empregos na indústria madeireira, Sobral na indústria de artigos de couro/calçadista e Macapá na indústria da construção. Volta Redonda completa a lista dos municípios mais especializados naquele ano, devido à alta participação da indústria metalúrgica em seus empregos industriais. Destas cidades, Santa Luzia, Altamira e Macapá podiam ser caracterizadas por possuírem baixo nível de concentração industrial e instrução, enquanto que Sobral, Altamira e Macapá possuíam os menores salário/hora médios. Por outro lado, Volta Redonda, 
que combinava alto grau de especialização com elevados níveis de salários e instrução, pode ser caracterizado como um município tipicamente marshalliano.

Tabela 2 - Mesopolos mais especializados e mais diversificados em 2001

\begin{tabular}{lc}
\hline Mesopolos & HH \\
\hline Santa Luzia & 0,779 \\
Sobral & 0,544 \\
Altamira & 0,362 \\
Volta Redonda & 0,345 \\
Macapá & 0,333 \\
Campinas & 0,026 \\
São José do Rio Preto & 0,026 \\
Rio de Janeiro & 0,025 \\
São Paulo & 0,018 \\
Londrina & 0,015 \\
\hline
\end{tabular}

Fonte: Elaboração própria com base em dados da RAIS.

Entre os mesopolos mais diversificados encontravam-se as duas cidades com maior concentração industrial nacional, São Paulo e Rio de Janeiro. Londrina e São José do Rio Preto se destacam como representantes das cidades médias no índice, possuindo, em 2000, cerca de 446 mil e 357 mil habitantes, respectivamente. Por fim, Campinas situava-se numa situação intermediária entre esses quatro municípios, com cerca de 968 mil habitantes naquele ano (IBGE, 2011). Destaca-se a situação de Londrina e São José do Rio Preto, que alcançaram um nível elevado de diversificação inclusive com Londrina liderando o índice nesse aspecto -, antes mesmo de se tornarem municípios grandes, o que revela que a diversificação não é necessariamente exclusividade de grandes metrópoles. Entretanto, os salários verificados para essas cidades encontravam-se apenas próximos da média. Já São Paulo, Rio de Janeiro e Campinas encontram-se entre os municípios com maior nível salarial.

A matriz dos componentes obtidos para 2010e as informações relacionadas à extração dos componentes são apresentados na Tabela 3. O percentual da variância total explicada pelos dois componentes para 2010 foi de 70,42\%, e os testes KMO e de esfericidade de Bartlett apresentam a adequação da amostra para o tratamento via ACP.

Os resultados demonstram uma forte relação positiva entre salário/hora, grau de instrução e concentração industrial no componente 1 , ao passo que o componente 2 revela correlação elevada entre a especialização produtiva e o emprego em grandes empresas. Essa distribuição das variáveis entre os componentes revela-se idêntica àquela obtida por Galinari et al. (2007), portanto optou-se por nomeá-las de acordo com o trabalho daqueles autores, onde o componente 1 é o do "desenvolvimento ur- 
bano-industrial", em que se presume a presença de economias de urbanização, levando a salários acima da média; enquanto que o componente 2 é o da "cidade-empresa".

Tabela 3 - Matriz de componentes principais para 2010

\begin{tabular}{l|c|c}
\hline \multirow{2}{*}{ Variável } & \multicolumn{2}{|c}{ Componente } \\
\cline { 2 - 3 } Salário/hora & $\mathbf{1}$ & $\mathbf{2}$ \\
\hline Grau de instrução & 0,862 & 0,237 \\
\hline Concentração industrial & 0,782 & $-0,031$ \\
\hline Especialização produtiva $(H H)$ & 0,646 & $-0,106$ \\
\hline Emprego em grandes empresas & $-0,262$ & 0,874 \\
\hline Adequação da amostra segundo critério KMO & 0,288 & 0,875 \\
\hline Significância do teste de esfericidade de Bartlett & & 0,523 \\
\hline Variância total explicada & & 0,000 \\
\hline
\end{tabular}

Fonte: Elaboração própria.

A mudança do componente 2, da "especialização industrial diversificada" em 2001 para a "cidade empresa" em 2010, pode estar associada a um movimento das grandes empresas, sobretudo aquelas relacionadas a setores mais tradicionais, em direção a pólos cuja concentração industrial é menor. Staduto et al. (2008) apontam para essa dinâmica no caso do Paraná, onde a região metropolitana permaneceu responsável pelos empregos em setores tecnologicamente mais dinâmicos, ao passo que na região nãometropolitana ocorreu um aprofundamento da especialização nas indústrias tradicionais, mais intensivas em mão de obra, como a indústria da madeira e mobiliário, têxtil, de calçados e de produtos alimentícios, bebidas e álcool etílico. Esse movimento, extrapolado do caso paranaense para o nacional, pode explicar a associação da presença de grandes empresas em municípios onde a especialização verifica-se mais elevada. De fato, em termos macrorregionais, Britto (2000), bem como Balanco e Santana (2007), apontam para uma intensificação de indústrias tradicionais no Nordeste, como a têxtil e a de alimentos e bebidas. Pari passu, os Estados do Sudeste, especialmente São Paulo, mantiveram uma estrutura industrial mais diversificada e com conteúdo tecnológico mais elevado. Tais movimentos das indústrias tradicionais, apesar de terem ocorrido em grande medida também na década de 1990, podem ter seus efeitos cristalizados apenas na década recente, impactando na mudança de dotação dos atributos verificada na ACP.

A Figura 3 apresenta os componentes de 2010 e a respectiva posição dos mesopolos. Em relação aos componentes de 2001, percebe-se uma rotação dos eixos em sen- 
tido horário, e visualiza-se que, em geral, a situação dos municípios permaneceu a mesma em relação aos atributos, acompanhando o movimento rotacional. A distribuição dos atributos mostra que, quanto mais acima do eixo horizontal estiver o mesopólo, mais acima da média estarão os seus valores relacionados ao componente do "desenvolvimento urbano-industrial", isto é, salário/médio por hora, nível de instrução e concentração industrial. Por sua vez, quanto mais os mesopolos estiverem à direita em relação ao eixo vertical, mais acima da média serão seus valores para as dotações dos atributos relativos ao componente da "cidade empresa", ou seja, emprego em grandes empresas e especialização produtiva.

Figura 3 - Os componentes principais de 2010

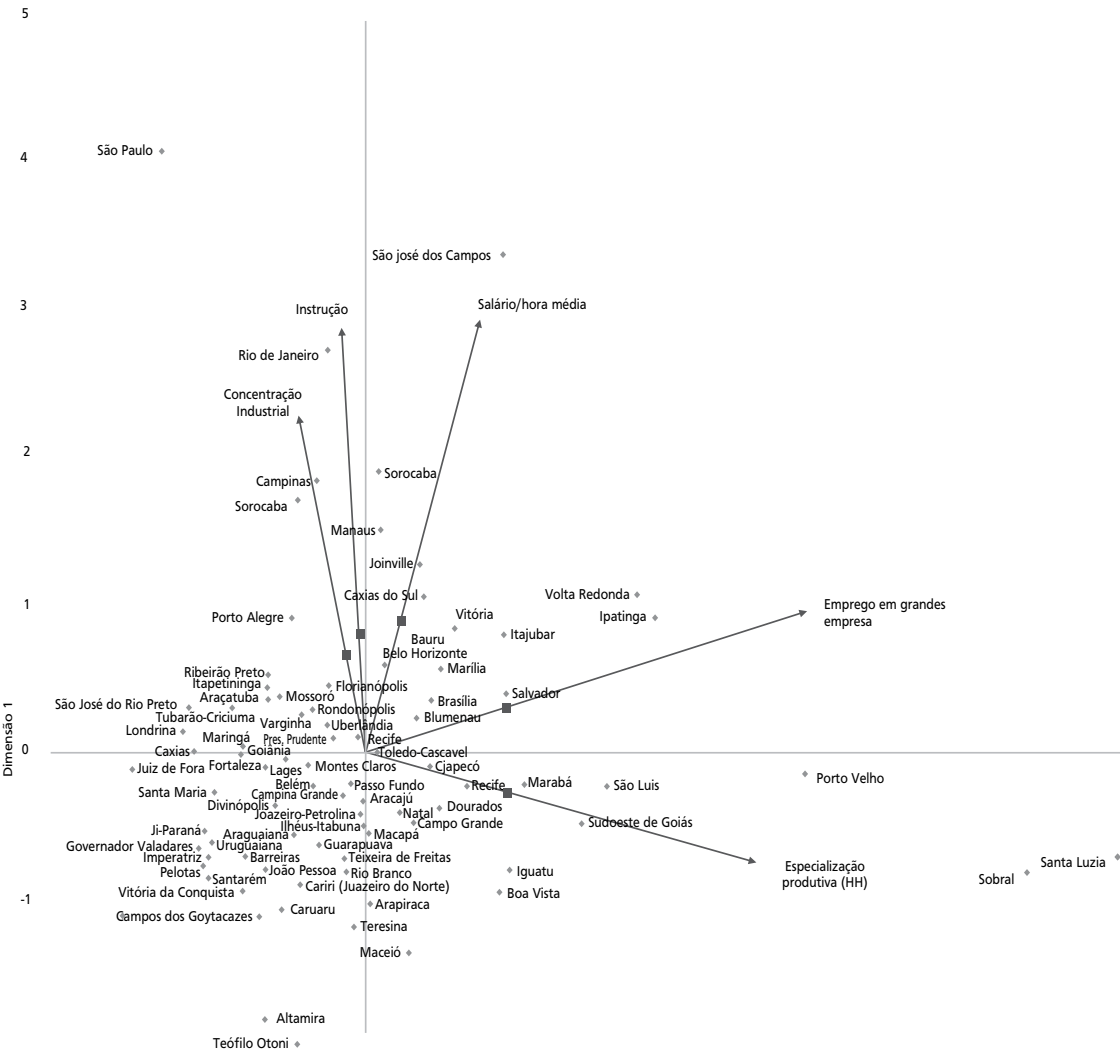

\footnotetext{
$-2$ 
Apesar de uma melhora generalizada nos índices de salário e educação, não ocorreram nesses dez anos grandes mudanças nas posições relativas dos mesopolos em questão. Das dez cidades com maior média de anos de instrução em 2010, seis já estavam nessa situação em 2001 (São José dos Campos, Sorocaba, Manaus, Joinville, Curitiba e Campinas), consolidando suas situações nesse aspecto. Entre as que não estavam na relação de 2001 (Itajubá, Florianópolis, Bauru e Caxias), merece destaque o mesopólo maranhense de Caxias, já que sua situação naquele período era justamente a oposta, quando era o quarto município com menor nível educacional. Ao longo desse período, os empregados na indústria do município praticamente triplicaram, sendo que o ramo industrial que mais ganhou relevância nesse contexto foi o de fabricação de produtos alimentícios, enquanto que a maior perda de participação ocorreu no setor de fabricação de produtos de minerais não metálicos. Ao mesmo tempo, o município sofreu um movimento de melhora em seu nível salarial médio na indústria, contudo ainda permanecendo abaixo da média dos municípios analisados. Dadas essas mudanças, a posição desse município sofreu uma considerável movimentação do gráfico de 2001 para o de 2010, saindo do limite inferior para localizar-se muito próximo à média das variáveis do "desenvolvimento urbano-industrial".

Quanto à média salarial, em comparação com 2001, não se visualizaram mudanças expressivas na situação dos municípios situados nos extremos do salário/hora médio. Em termos de distância relativa entre os extremos, enquanto que em 2001 o salário do extremo inferior representava apenas $11,94 \%$ do salário do limite superior, em 2010 essa situação sofreu apenas uma modesta melhora, passando o salário inferior a representar 15,9\% do superior. Além disso, os cinco piores salários estão localizados na região Nordeste, ao passo que os cinco melhores pertencem todos ao Sudeste.

No agregado, os 84 mesopolos sofreram uma ligeira queda na participação dos empregos na indústria nacional. Enquanto que em 2001 representavam 38,91\% dos empregos industriais, em 2010 esse valor reduziu-se para 37,65\%. A maior redução individual de participação ocorreu no município de São Paulo, que respondia por 9,74\% do emprego na indústria em 2001, passando para 7,78\% em 2010. Entre os municípios que mais ganharam participação, aparecem Porto Velho, Manaus e Salvador, em respectiva ordem de ganho.

Os cinco municípios mais especializados e os cinco mais diversificados em 2010, conforme o índice $\mathrm{HH}$, são apresentados na Tabela 4. Dos mesopolos mais especializados, Sobral e Santa Luzia já figuravam nessa condição em 2001, enquanto que Porto Velho, São Luís e Boa Vista intensificaram-se na especialização em um mesmo setor, no caso o da indústria da construção. No outro extremo, Londrina e São José do Rio Preto mantiveram-se entre os mesopolos mais diversificados. Já Maringá, Juiz de Fora e Curitiba, apesar de não figurarem entre os cinco mais diversificados em 2001, já possuíam então um grau elevado de diversidade industrial, e avançaram nesse processo ao longo da década. 
Tabela 4 - Municípios mais especializados e mais diversificados em 2010

\begin{tabular}{lc}
\hline Cidade & HH \\
\hline Sobral & 0,660 \\
Santa Luzia & 0,605 \\
Porto Velho & 0,416 \\
São Luis & 0,331 \\
Boa Vista & 0,292 \\
\hline Maringá & 0,023 \\
Juiz de Fora & 0,020 \\
Curitiba & 0,018 \\
São José do Rio Preto & 0,017 \\
Londrina & 0,014 \\
\hline
\end{tabular}

Fonte: Elaboração própria com base em dados da RAIS.

Chamam a atenção dois fatos nessas cinco cidades: i) três localizam-se no estado do Paraná; e ii) somente uma pode ser considerada uma grande metrópole urbana, no caso, Curitiba. As demais cidades estão em estágio intermediário entre médias e grandes, sendo Juiz de Fora a maior delas, com cerca de 516 mil habitantes, de acordo Censo do IBGE (2010), reforçando o ponto já afirmado anteriormente, de que uma cidade não precisa necessariamente atingir a condição de grande metrópole para atingir um elevado grau de diversificação.

De uma maneira geral, observou-se nesse contexto foi o fato de que, apesar do período de crescimento nacional verificado na última década, a heterogeneidade salarial da indústria dos mesopolos analisadas pouco se alterou, bem como não houve grandes alterações nas economias de aglomeração que se verificavam no início da década. O crescimento do emprego formal na indústria como um todo promoveu uma expansão dos postos de trabalho em quase todos os seus setores, mas alguns setores naturalmente ganharam mais do que outros nesse processo.

A Tabela 5, que apresenta os mesopolos mais especializados em 2010, o respectivo setor mais especializado, e a proporção dos salários no setor especializado em comparação aos salários pagos nos demais setores industriais daquele mesopólo. Dentre os 20 mesopolos mais especializados em 2010, 11 eram especializados no setor da construção civil. Contudo, verifica-se que, em vários casos, os salários pagos nesse setor estavam, em média, abaixo daquele pago nos demais setores dos respectivos mesopolos. No caso de Vitória, por exemplo, os salários pagos na construção representam apenas $31,6 \%$ do salário médio pago nos seus demais setores industriais. Por outro lado, Santa Luzia aparece no outro extremo, cujos salários na construção eram mais de três vezes superior aos demais salários industriais - o que, contudo, não pode ser considerado em termos absolutos, já que os empregos criados nesse setor, além de representarem a quase totalidade dos empregos industriais naquele município, são oriun- 
dos de um consórcio de construtoras que estão na cidade apenas para realizar obras de recuperação da BR 222, ou seja, são instalações de caráter temporário cuja demanda é oriunda de investimentos governamentais não exclusivos ao município. Desconsiderando o caso de Santa Luzia, visualiza-se que o município onde os salários do setor especializado são mais superiores aos demais é Volta Redonda, cujo setor especializado é o da metalurgia básica, um setor que, por ser muito mais avançado tecnologicamente do que aqueles mais básicos - como os setores de couro, vestuário, alimentos e bebidas -, então tal como sugere Henderson (1999), possui economias internas de escala maiores, possibilitando o pagamento de salários mais elevados.

Tabela 5 - Mesopolos mais especializados em 2010 e salários pagos no setor especializado em comparação com os demais setores industriais

\begin{tabular}{|c|c|c|}
\hline Mesopolo & Setor especializado & $\begin{array}{l}\text { Salário do setor especializado/ } \\
\text { salário dos demais setores }\end{array}$ \\
\hline Vitória & Construção & 0,316 \\
\hline Aracaju & Construção & 0,485 \\
\hline Salvador & Construção & 0,545 \\
\hline $\mathrm{BH}$ & Construção & 0,677 \\
\hline São Luis & Construção & 0,691 \\
\hline Caruaru & Confec. de artigos do vestuário e acessórios & 0,768 \\
\hline Sobral & $\begin{array}{l}\text { Prep. de couros e fabr. de artefatos de couro, } \\
\text { artigos de viagem e calçados }\end{array}$ & 0,819 \\
\hline Teófilo Otoni & Construção & 0,868 \\
\hline Juazeiro do Norte & $\begin{array}{l}\text { Prep. de couros e fabr. de artefatos de couro, } \\
\text { artigos de viagem e calçados }\end{array}$ & 0,872 \\
\hline Sudoeste de Goiás & Fabr. de produtos alimentícios e bebidas & 0,878 \\
\hline Ipatinga & $\begin{array}{l}\text { Fabr. de produtos de metal - exclusive máquinas } \\
\text { e equipamentos }\end{array}$ & 0,949 \\
\hline Blumenau & Fabr. de produtos têxteis & 1,008 \\
\hline Iguatu & $\begin{array}{l}\text { Prep. de couros e fabr. de artefatos de couro, } \\
\text { artigos de viagem e calçados }\end{array}$ & 1,031 \\
\hline Boa Vista & Construção & 1,099 \\
\hline Arapiraca & Fabr. de produtos alimentícios e bebidas & 1,134 \\
\hline Brasília & Construção & 1,174 \\
\hline Macapá & Construção & 1,594 \\
\hline Porto Velho & Construção & 1,685 \\
\hline Volta Redonda & Metalurgia básica & 2,445 \\
\hline Santa Luzia & Construção & 3,345 \\
\hline
\end{tabular}

Fonte: Elaboração própria com base em dados da RAIS. 
Cabe apontar, de maneira geral, as cidades mais especializadas em ambos os períodos constituem centros menores e de níveis de renda per capita relativamente baixos se comparados aos grandes centros da amostra. Desta forma, faz sentido retornar à ideia da relação em forma de "U" entre especialização e renda proposta por Imbs e Wacziarg (2003), bem como se percebem semelhanças com os resultados de Catela, Gonçalves e Porcile (2010). Assim, em tais municípios, a estratégia que possibilita maiores ganhos salariais ainda é diversificação, ao passo que para as cidades maiores - e já mais diversificadas - tal constatação não é necessariamente verdadeira.

\subsection{ANÁLISE DE REGRESSÃO: CORRELAÇÃO ENTRE ECONOMIAS DE AGLOMERAÇÃO E SALÁRIO INDUSTRIAL NOS MESOPOLOS BRASILEIROS}

Para verificar a existência de correlações entre as economias de aglomeração e os salários industriais, bem como suas respectivas intensidades, realizaram-se regressões para os anos de 2001 e 2010, utilizando o método dos mínimos quadrados ordinários (MQO).

Inicialmente os resultados revelaram a presença de heterocedasticidade, isto é, variância não constante dos erros estimados, afetando a interpretação da significância das variáveis independentes. Como forma de eliminar a heterocedasticidade, procedeu-se com a estimação por mínimos quadrados generalizados (MQG), gerando assim estimadores que podem ser considerados os melhores estimadores lineares não tendenciosos (Greene, 2012).

A Tabela 6 apresenta o resultado das estimações econométricas realizadas para os anos de 2001 e 2010. Os resultados apresentados mostram-se consistentes para esses dois anos, e o modelo revelou um bom nível de ajuste em ambos os períodos. A variável anos de estudo apresentou nos dois anos uma forte correlação positiva com os salários médios industriais, de forma que uma elevação de $1 \%$ nos anos de estudo levava, em média, a um acréscimo nos salários de 2,8\% em 2001, e de 1,6\% em 2010. Em ambos os anos essa variável revelou-se significativa ao nível de 1\%, reforçando o resultado já encontrado na ACP, onde os anos de estudo revelaram-se como a variável mais fortemente associada aos salários mais elevados nos dois momentos. Esse resultado revela-se de acordo com a teoria do capital humano, na qual um maior nível de educação do indivíduo leva, em geral, a maiores salários, seja diretamente, pelo aumento de sua habilidade cognitiva e de sua produtividade, seja pelo "sinal" que essa informação produz no mercado de trabalho (Lima, 1980). Ainda, é preciso atentar para a redução da magnitude da variável entre esses anos, sinalizando uma redução do impacto da educação sobre o salário industrial em 2010. 
Tabela 6 - Resultados das regressões por MQG para 2001 e 2010

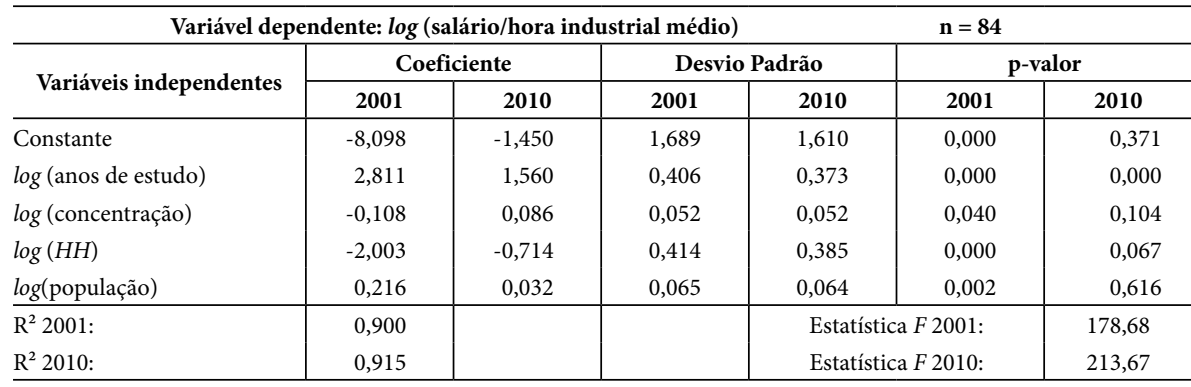

Fonte: Elaboração própria.

A variável concentração industrial foi estatisticamente não significante para 2010, portanto não impactando na variação da taxa salarial daquele ano. No entanto, em 2001 essa variável foi significativa e negativa, de forma que, na média, o aumento da concentração impacta negativamente na taxa salarial industrial, ou seja, um mesopólo cuja participação do emprego industrial nacional era 100\% maior que outro, apresentou salários 10,8\% menores, o que indica a presença de deseconomias de aglomeração. Comparando-se esse resultado com aqueles verificados por Galinari et al. (2007) que, considerando as mesmas variáveis, encontrou salários 5\% mais altos em 1991 e 8\% mais altos em 2000, verifica-se uma discrepância nos efeitos da concentração da atividade industrial sobre os salários no início da primeira década deste milênio. Cabe lembrar que tal diferença pode-se dever tanto à diferença entre as bases de dados utilizados, quanto pela inclusão de uma variável de controle adicional no presente estudo (população).

Deve-se notar que as cidades com maior concentração da indústria são também os maiores centros populacionais do país, onde é natural que os salários sejam mais elevados em função do maior custo de vida e das desvantagens socioambientais de se habitar nesses centros. Em 2001 tal efeito foi capturado pelo coeficiente positivo da variável população, indicando que, naquele ano, uma cidade com o dobro da população de outra tendia a ter salários 21,6\% maiores. Já em 2010 tal variável não se apresentou significativa, indicando que as diferenças entre os tamanhos dos pólos da amostra podem ter deixado de ser fator significante para a determinação do salário do trabalhador industrial.

Por fim, os coeficientes da variável $\mathrm{HH}$ foram significativos a 1\% em 2001 e a 6,7\% em 2010. O sinal negativoem ambos os anos expressa, na média, que quanto mais especializado é um mesopolo, menores são os seus salários industriais, contrariando as teorias de especialização/localização, mas em conformidade com a diversificação/urbanização teorizada por Jacobs (1969). A magnitude do efeito reduziu-se ao longo da década, demonstrando um possível arrefecimento das economias de urbanização entre 
os períodos sem, entretanto, alterar a direção e a interpretação do efeito. Dessa forma, o que se verifica no caso brasileiro é que, em geral, as cidades mais diversificadas em suas atividades industriais possuem salários maiores, como resultado das economias de urbanização decorrentes. Jacobs (1969) faz uma analogia com a embriologia, onde um dos maiores debates por muito tempo foi entre os propositores da "pré-formação" e aqueles que defendiam a "epigênese". Os primeiros erroneamente acreditavam que o desenvolvimento de um embrião era simplesmente um processo de crescimento das partes que já existiam, enquanto que os proponentes da epigênese defendiam que o desenvolvimento embrionário era um processo de gradual diversificação e diferenciação de tecidos a partir de uma entidade inicialmente não diferenciada. Com o tempo, provou-se que estes últimos estavam certos. Da mesma forma, para a autora, as cidades não se mantêm crescendo por um processo de "pré-formação", mas sim através de uma "epigênese", diversificando e diferenciando gradualmente sua economia.

Ainda sobre a respeito da diminuição do coeficiente da variável $\mathrm{HH}$, pontua-se que Galinari et al. (2007) mostram que entre 1991 e 2000 ocorreu um movimento inverso, onde a especialização tornou-se fator de maior prejuízo aos assalariados, o que eles associam ao quadro de mudanças na distribuição espacial da indústria, sobretudo das tradicionais, promovido pela abertura econômica ocorrida naquela década. Tais deslocamentos locacionais buscaram, de maneira geral, a redução de custos, motivados pela possibilidade de obter mão de obra mais barata. Considerando essa relação, é possível verificar que no período de 2001 a 2010, o impacto desse tipo de estratégia sobre os salários industriais, apesar de ainda presente, diminuiu.

De modo geral, os resultados aquiencontrados a respeito da especialização/diversificação contrariam aqueles encontrados por autores como Henderson (1999), Van der Panne (2004) e Wheaton e Lewis (2002), onde as economias de especialização/localização marshallianas revelaram-se mais relevantes. Contudo, é preciso pontuar que esses autores realizaram seus estudos em economias mais desenvolvidas industrialmente, ao passo que os resultados da análise do caso brasileiro ainda podem ser considerados incipientes. Nesse sentido, os resultados encontrados no presente estudo revelam-se em concordância com aqueles obtidos por Galinari et al. (2007), que consideraram o caso brasileiro entre 1991 e 2000.

\section{CONSIDERAÇÕES FINAIS}

A trajetória da economia brasileira a partir dos anos 2000 caracteriza-se por um crescimento econômico mais elevado do que aquele verificado na década anterior, crescimento esse assentado, sobretudo, na estabilidade econômica e na expansão dos merca- 
dos internos e externos, conjuntamente com gastos públicos em políticas sociais. Nesse contexto, no caso brasileiro verificou-seque as economias de aglomeração se mostram presentes e relevantes, em especial as economias de urbanização/diversificação/Jacobs, de forma que, em média, as cidades cuja indústria é mais diversificada possuem salários mais elevados. Esse resultado aproxima-se da abordagem teórica de Jacobs (1969), ou seja, é a diversidade produtiva que mantém a possibilidade de crescimento urbano sustentável no longo prazo.

A associação mais forte encontrada foi a dos salários em relação ao nível educacional do trabalhador. De maneira geral, é mais comum encontrar níveis de instrução mais elevados em indústrias com maior conteúdo tecnológico, ao passo que setores mais intensivos em mão de obra não demandam o mesmo nível de instrução. Essas indústrias mais desenvolvidas tecnologicamente também tendem a se concentrar nos grandes pólos e nas proximidades da região metropolitana de São Paulo, assim como nas demais regiões metropolitanas, ao passo que os setores tradicionais são mais comumente encontrados no interior dos Estados, e mais afastados das áreas de influência das regiões metropolitanas, o que evidencia essa dualidade ainda presente no país: grandes regiões metropolitanas constituem loci mais adequados às atividades que exigem maiores níveis educacionais, e possuem assim, em média, salários mais elevados, ao passo que as regiões mais interioranas e as cidades de menor porte acabam se especializando em setores tradicionais, mais intensivos em mão de obra, com menor requisito educacional e, assim, com maior probabilidade de pagar salários menores. Desta maneira, apesar de ter ocorrido uma relativa desconcentração dos empregos industriais dos grandes pólos na última década, essa desconcentração não foi fator suficiente para alterar de maneira substancial a estrutura salarial dos polos considerados nesta pesquisa.

Essas constatações fornecem luz quanto à necessidade de políticas de desenvolvimento regional adequadas a cada contexto, e que levem em consideração o fato verificado de que o incentivo à especialização não necessariamente irá reduzir as imensas disparidades regionais brasileiras. Apesar da expansão dos empregos formais na última década certamente ter beneficiado muitos trabalhadores, a especialização produtiva de certas cidades pode, na verdade, aprofundar a desigualdade salarial, na medida em que a desconcentração se der predominantemente em setores tradicionais e buscando pagar salários menores.

Aponta-se, simultaneamente, para a importância de políticas educacionais e de qualificação da mão de obra que sejam concomitantes a medidas que levem à criação de postos de trabalho de maior qualidade nas cidades menores e menos desenvolvidas, evitando que a mão de obra qualificada deixe esses locais para buscar empregos melhores nas grandes metrópoles. Não basta investir em instrução se não há a criação 
simultânea de postos de trabalho que possam absorver esses trabalhadores mais qualificados, de preferência em localidades onde a pobreza é maior, contribuindo dessa maneira para a redução da carência destes lugares e da desigualdade regional tão característica no cenário brasileiro.

\section{REFERÊNCIAS}

ANDRADE, T. A.; SERRA, R. V. O recente desempenho das cidades médias no crescimento populacional urbano brasileiro. Texto para Discussão, IPEA, Rio de Janeiro, n. 554, 1998.

BALANCO, P. A. F.; SANTANA, G. A. indústria de transformação do Nordeste no período 1994-2005: uma análise espacial e estrutural. Revista Desenbahia, v. 7, p. 87-103, 2007.

BEAUDRY, C.; SCHIFFAUEROVA, A. Who's right, Marshall or Jacobs? The localization versus urbanization debate. Research Policy, v. 38, n. 2, p. 318-337, 2009.

BRITTO, J. Características estruturais dos clusters industriais na economia brasileira. Projeto de pesquisa "Arranjos e sistemas produtivos locais e as novas políticas de desenvolvimento industrial e tecnológico". Nota Técnica n. 29/00. Rio de Janeiro: IE-UFRJ, 2000.

CARLEIAL, L. M. F. Firmas, flexibilidades e direitos no Brasil: para onde vamos? São Paulo em Perspectiva, v. 11, n. 1, p. 22-33, 1997.

CARVALHO, L.; KUPFER, D. Diversificação ou especialização: uma análise do processo de mudança estrutural da indústria brasileira. Revista de Economia Política, v. 31, n. 4, p. 618637, 2011.

CASTRO, A. B. A reestruturação industrial brasileira nos anos 90: uma interpretação. Revista de Economia Política, v. 21, n. 3, p. 3-25, 2001.

CATELA, E. Y. S.; GONÇALVES, F.; PORCILE, G. Brazilian municipalities: agglomeration economies and development levels in 1997 and 2007. Cepal Review, n. 101, p. 141-156, 2010.

DEKLE, R. Concentration and regional growth: evidence from the prefectures. The Review of Economics and Statistics, v. 84, n. 2, p. 310-315, 2002.

DINIZ, C. C. Desenvolvimento poligonal no Brasil: nem desconcentração nem contínua polarização. Nova Economia, v. 3, n. 1, p. 35-64, set. 1993.

DINIZ, C. C.; CROCCO, M. A. Reestruturação econômica e impacto regional: o novo mapa da indústria brasileira. Nova Economia, v. 6, n. 1, p. 77-104, jul. 1996.

FUJITA, M.; KRUGMAN, P.; VENABLES, A. J. Economia espacial: urbanização, prosperidade econômica e desenvolvimento humano no mundo. São Paulo: Futura, 2002.

FURTADO, A. T.; CARVALHO, R. Q. Padrões de intensidade tecnológica da indústria brasileira: um estudo comparativo com os países centrais. São Paulo em Perspectiva, v. 19, n. 1, p. 70-84, 2005.

GALINARI, R.; CROCCO, M. A.; LEMOS, M. B.; BASQUES, M. F. D. O efeito das economias de aglomeração sobre os salários industriais: uma aplicação ao caso brasileiro. Revista de Economia Contemporânea, v. 11, n. 3, p. 391-420, set./dez. 2007. 
GLAESER, E. L.; KALLAL, H. D.; SCHEINKMAN, J. A.; SHLEIFER, A. Growth in cities. The Journal of Political Economy, v. 100, n. 6, p. 1126-1152, 1992.

GREENE, W. H. Econometric analysis. 7. ed. New Jersey: Prentice Hall, 2012.

HANSON, G. H. Increasing returns, trade and the regional structure of wages. The Economic Journal, v. 107, n. 440, p. 113-133, 1997.

HENDERSON, J. V. Marshall's scale economies. Working Paper, NBER, n. 7358, Sept. 1999.

HENDERSON, J. V.; KUNCORO, A.; TURNER, M. Industrial development in cities. The Journal of Political Economy, v. 103, n. 5, p. 1067-1090, 1995.

HO, R. Handbook of univariate and multivariate data analysis and interpretation with SPSS. Boca Raton: Chapman \& Hall, 2006.

HOFFMANN, R. Componentes principais e análise fatorial. ESALQ/USP: Piracicaba, 1999. mimeo.

IMBS, J.; WACZIARG, R. Stages of diversification. American Economic Review, v. 93, n. 1, p. 6386, 2003.

INSTITUTO BRASILEIRO DE GEOGRAFIA E ESTATÍSTICA (IBGE). Censo Demográfico 2000. 2011. Disponível em: <http://www.sidra.ibge.gov.br/cd/cd2000sp.asp?o=7\&i=P>. Acesso em: 02 out. 2011.

INSTITUTO BRASILEIRO DE GEOGRAFIA E ESTATÍSTICA (IBGE). Censo Demográfico 2010. 2010. Disponível em: <http://www.sidra.ibge.gov.br/cd/cd2010 sp.asp?o=3\&i=P>. Acesso em: 03 out. 2011.

JACOBS, J. The economy of cities. Nova York: Random House, 1969.

KAULICH, F. Diversification vs. specialization as alternative strategies for economic development: can we settle a debate by looking at the empirical evidence? Working Paper, UNIDO, Development Policy, Statistics and Research Branch, n. 3, 2013.

KEMENY, T.; STORPER, M. Specialization and regional economic development. Discussion Paper, Spatial Economics Research Centre, n. 121, 2012.

LEMOS, M. B.; DINIZ, C. C.; GUERRA, L. P.; MORO, S. A nova configuração regional brasileira e sua geografia econômica. Estudos Econômicos, v. 33, n. 4, 2003.

LIMA, R. Mercado de trabalho: o capital humano e a teoria da segmentação. Pesquisa e Planejamento Econômico, v. 10, n. 1, p. 217-272, 1980.

LIMA, R.S. Notas à margem da estrutura industrial do Rio Grande do Sul. Ensaios FEE, Porto Alegre, v. 24, n. 1, p. 49-92, 2003.

MARICATO, E. Brasil, cidades: alternativas para a crise urbana. Petrópolis: Vozes, 2001.

MARSHALL, A. Principles of economics: an introductory volume. 8. ed. Londres: Macmillan and Co., 1920.

NEGRI, B. Concentração e desconcentração industrial em São Paulo (1880-1990). Campinas: Editora da Unicamp, 1996.

PASSOS, M.C.; LIMA, R. S. “Tendências estruturais da indústria gaúcha nos anos 90: sintonias e assimetrias”. In: FLIGENSPAN, F.B. (Org.) Economia gaúcha e reestruturação nos anos 90. Porto Alegre: FEE, 2000, p. 117-158. 
PROGRAMA DAS NAÇÕES UNIDAS PARA O DESENVOLVIMENTO (PNUD). Brasil sobre quatro posições no novo IDH. Disponível em: <http://www.pnud.org.br/pobreza _desigualdade/reportagens/index.php?id01=3596\&lay=pde\#>. Acesso em: 2 mai. 2011.

RAUCH, J. E. Productivity gains from geographic concentration of human capital: evidence from the cities. Working Paper, NBER, n. 3905, Nov. 1991.

REZENDE, A. C.; CAMPOLINA, B.; PAIXÃO, A. N. Clusterização e localização da indústria de transformação no Brasil entre 1994 e 2009. Revista Econômica do Nordeste, v. 43, n. 4, p. 27-49, 2012.

SABÓIA, J. Descentralização industrial no Brasil na década de noventa: um processo dinâmico e diferenciado regionalmente. Nova Economia, v. 11, n. 2, dez. p. 85-122, 2001.

SERVIÇO BRASILEIRO DE APOIO ÀS MICRO E PEQUENAS EMPRESAS (SEBRAE). Critérios de classificação de empresas. [on-line] Disponível em < http://www.sebrae-sc.com.br/ leis $/$ default.asp?vcdtexto=4154>. Acesso em: 26 mai. 2011.

SIMÕES, R.; AMARAL, P. V. Interiorização e novas centralidades urbanas: uma visão prospectiva para o Brasil. Economia, v. 12, n. 3, p. 553-579, 2011.

SPEROTTO, F. Q.; PEYRÉ-TARTARUGA, I. G. A concentração espacial do emprego formal e da massa salarial no Rio Grande do Sul: metodologia e tipologia. Textos para Discussão, FEE, Porto Alegre, n. 61, 2009.

STADUTO, J. A. R.; FERRERA DE LIMA, J. MALDANER, I. STAMM, C. Análise locacional das ocupações nas regiões metropolitana e não-metropolitana do estado do Paraná. Revista de Economia, v. 34, n. 2, p. 117-139, 2008.

SUZIGAN, W.; FURTADO, J.; GARCIA, R.; SAMPAIO, S. E. K. Aglomerações industriais no estado de São Paulo. Revista de Economia Aplicada, v. 5, n. 14, p. 695-717, 2001.

VAN DER PANNE, G. Agglomeration externalities: Marshall versus Jacobs. Journal of Evolutionary Economics, v. 14, n. 5, p. 593-604, 2004.

WEBER, A. Theory of the location of industries. Chicago: University of Chicago Press, 1929.

WHEATON, W. C.; LEWIS, M. J. Urban wages and labor market agglomeration. Journal of Urban Economics, v. 51, p. 542-562, 2002. 